\title{
PROSTHETIC IMPLANT MAP (PIM) - ACCURATE AND CONVENIENT ASSISTANT IN SUCCESSFUL IMPLANT TREATMENT
}

\author{
Neli Nikolova, Dimitar Filchev, \\ Department of Prosthetic Dentistry, Faculty of Dental Medicine, Medical \\ University - Sofia, Bulgaria.
}

\begin{abstract}
Objective: This article presents a prosthetic map of implant dental treatment, which aims to systematize and archive the detailed information concerning the prosthetic aspect of implant treatment.

Material and Methods: A survey about peri-implant soft tissues (PIST) was carried out among 31 dental practitioners experienced in implantology. Opinions were expressed about the significance of their specific characteristics in the creation of the implant supra-structure. A practical test for recognition of specific characteristics was performed by four dentists with a different level of experience in implant-supported prosthodontics, who have been thoroughly informed and instructed how to report the PIST status parameters in 10 implant sites. The analysed results were used as a base for the map criteria.

Result: A prosthetic map was created with the following sections containing: 1) personal data with brief information about the patient, 2) information about the implant, 3) information about peri-implant alveolar bone, 4) information about PIST, 5) information about the planned implant restoration,6) information about follow-up examinations.

Conclusion: The organization and formatting of the map allow very accurate marking of all data important for the implant prosthetic treatment and their follow-up over time. The Prosthetic implant map can be used as a guideline for implant supra-structure planning. From a practical point of view, it is a very convenient way of storing all the necessary information and its subsequent analysis for both clinician and patient.
\end{abstract}

Keywords: prosthetic implant treatment, peri-implant soft tissue, prosthetic implant map,

\section{INTRODUCTION}

The replacement of missing teeth with dental implants and their subsequent prosthetic restoration is a longestablished approach in clinical practice. In the last decade, the final result of implant treatment has become highly predictable, which is due both to the advancement in the technologies and materials used and to the observation of precise clinical and laboratory protocols. The latter include surgical, prosthetic and laboratory stages. The number and sequence of the manipulations at each stage varied according to the particular clinical case and the specifics of the implant system used. The condition analysis of the patient's masticatory system and the hard and soft tissues characteristics in the area of implant treatment are fundamental for stage planning.

In a number of studies, attention is focused on surgical protocols associated with both implant placement and augmentation of the peri-implant alveolar bone and mucosa. The prosthetic phase is examined from the perspective of: a) implant - implant supra-structure relation, b) the time of its elaboration (interim or permanent), c) the materials of which it is made and d) the interaction with the peri-implant soft tissues. [1,2]

Peri-implant soft tissue (PIST) status and behaviour are described and traced for a certain period of time after placing the permanent implant restoration. Covani U. et al. [3], monitors the soft tissue stability of about 15 implants placed without incisions and flap elevation, and result in successful osteointegration. The results are based on the clinical measurements of: a) the width of the keratinized tissue, b) the mucogingival junction level, c) the level of interdental papilla IP and d) periapical X-ray of the periimplant alveolar bone. All measurements are obtained with a standard periodontal probe and rounded to the nearest millimetre. Priest G. [4] examined and measured the periimplant mucosa using 1:1 scale photographic images which include the implant-supported restorations and at least one adjacent medial and distal tooth. Kan et al. [5] is among the authors who thoroughly explores the peculiarities and behaviour of PIST. One of their studies covered a 4-year period (range 2 to 8.2 years), with the main change in the peri-implant mucosal margin buccally $(-1.13 \mathrm{~mm})$ significantly higher than that seen in the one-year follow-up period $(-0.55 \mathrm{~mm})$. The assumption is that the recession of soft tissue buccally is a dynamic process and may last more than 12 months after the dental implant has been placed. Several studies have examined changes in soft tissue levels after prosthetic implant restoration placement and assessed the functional and aesthetic outcome. [5 - 13]

Peri-implant tissue, which is masticatory mucosa adapted to different implant systems as Lambert summarises, must be carefully maintained through good oral hygiene and proper soft tissue handling using soft-tissue- 
friendly prosthodontics. [14]

Therefore, the purpose of this study is not only to highlight the characteristics of peri-implant soft tissues prior to the prosthetic phase of treatment but also to match the design and materials of the implant-supported prosthetic restoration to them. This requires correct registration and observation of a standardized protocol in order to facilitate their follow-up over time.

\section{MATERIALS AND METHODS}

Two approaches were defined to achieve the goal:

I. An anonymous poll was conducted among 31 dental practitioners with a different level of experience in the field of implantology. The question they had to answer was: "Which of the characteristics of peri-implant soft tissues (PIST) would you consider when planning implant-supported prosthetic restoration?" The characteristics of PIST: 1) Colour of PIST); 2) Texture of PIST; 3) Density of PIST; 4) Width of the keratinized PIST; 5) Height of PIST from the implant platform; 6) Thickness of PIST Buccally; 7) Thickness of PIST Buccally and Lingually; 8) The thickness and height of PIST Mesially and Distally, were arranged in a table, which allowed them to be easily marked. [Fig. 1]
Fig. 1. Peri-implant soft tissue parameters included in the poll

parameter

peri-implant soft tissue colour

peri-implant soft tissue texture

peri-implant soft tissue consistency

keratinized peri-implant soft tissue width

peri-implant soft tissue thickness buccally

peri-implant soft tissue thickness buccally and lingually

peri-implant soft tissue height from implant platform

peri-implant soft tissue height and width mesially and distally

II. Four dentists with a different level of experience in implant-supported prosthodontics have been thoroughly informed and instructed how to report the PIST status parameters in 10 implant sites. The characteristics of peri-implant soft tissues were derived from the features of clinically healthy gingiva around natural teeth. The dentists were designated as A, B, C, D according to:

- General professional experience expressed in years of actual service.

- Professional experience in implant prosthodontics expressed in years.

- Number of implants, placed and restored for this period, indicated with approximate precision. [Fig. 2]

Fig. 2. The four dentists, according to their professional experience and experience in prosthetic implant treatment .

\begin{tabular}{ccccc}
\hline PIST dentist & A & B & C & D \\
\hline $\begin{array}{c}\text { parameter } \\
\text { profesional experience in } \\
\text { years }\end{array}$ & 22 & 18 & 11 & 4 \\
\hline $\begin{array}{c}\text { profesional experience in } \\
\text { implant prosthodontic in } \\
\text { years }\end{array}$ & 10 & 5 & 3 & 2 \\
\hline $\begin{array}{c}\text { number of placed and } \\
\text { restored implants }\end{array}$ & 200 & 40 & 15 & 5 \\
\hline
\end{tabular}

Each dentist was provided with detailed information about completing the table with PIST parameters using a legend for it. A methodology was applied to report the extent of occurrence of relevant signs detailed in Figure3. Numbers 1 to 3 categorized the degree of each parameter, and a 0 state that did not match any of the subgroups indicated for each parameter. The height and thickness of the PIST were directly measured by a periodontal probe.

A total sample size of 10 implant sites in the maxilla and mandibula were selected from 3 patients ( 3 males), who needed implant placement, with an age range of 48 63 years.

Before implant placement and subsequent restoration, thorough medical history was taken from all the patients. Each case was precisely evaluated by a thorough examination of intraoral status and periapical radiographs. The inclusion criteria were cases of apparently healthy in- dividuals with sufficient alveolar bone height and width; those who could maintain satisfactory oral hygiene were included in the study. Patients with any medical compromise or bone condition, with a history of any oral mucosal diseases, osseous defects, severe periodontal problems, and cases with a history of chronic alcoholism, smoking, or teeth grinding were excluded from the study. Consent was obtained from all the patients.

The distribution of the implant areas was as follows: 5 implants placed in the upper jaw in the position of teeth 16, 15/ 25, 26, 27 - 3Tissue level implants and 2 Bone level implants Straumann (Straumann Holding AG, Basel, Switzerland); 5 implants placed in the lower jaw in the position of teeth 46,44/34, 36, 37 - 2 Tissue level implants Straumann, 1 Swiss plus implant Zimmer Biomet (Zimmer Biomet, Warsaw, Indiana, USA), 1 Bone level implant Straumman and 1 TSV implant Zimmer Biomet. The chosen implant sites include different PIST phenotypes pro- 
viding a wide variety of the parameters studied.

A necessary condition for PIST characteristics registration was the lack of evidence of an inflammatory process in peri-implant tissues (alveolar bone and mucosa) as well as radiological and clinically established osteointegration of the implant. It was done by four dentists informed and trained in registering them at the stage of the completed healing process after the second surgery and at the stage of making the permanent implant-supported restorations after modification of PIST architectonics by emergence profile of the implants provisionals.

Observed PIST parameters were divided into two groups:

- Established organoleptically- included PIST colour and PIST texture [fig. 4]. They were reported by codes 1,2 and 3, relevant to the extent of their display, presented in the legend [Fig. 3]

Fig. 3. The legend with detailed information and degree of PIST parameters expression.

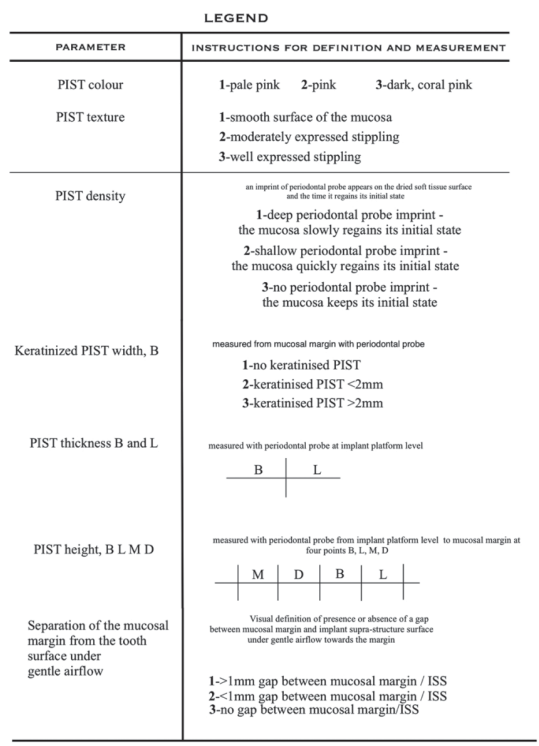

Fig. 4. PIST colour and texture assessment.

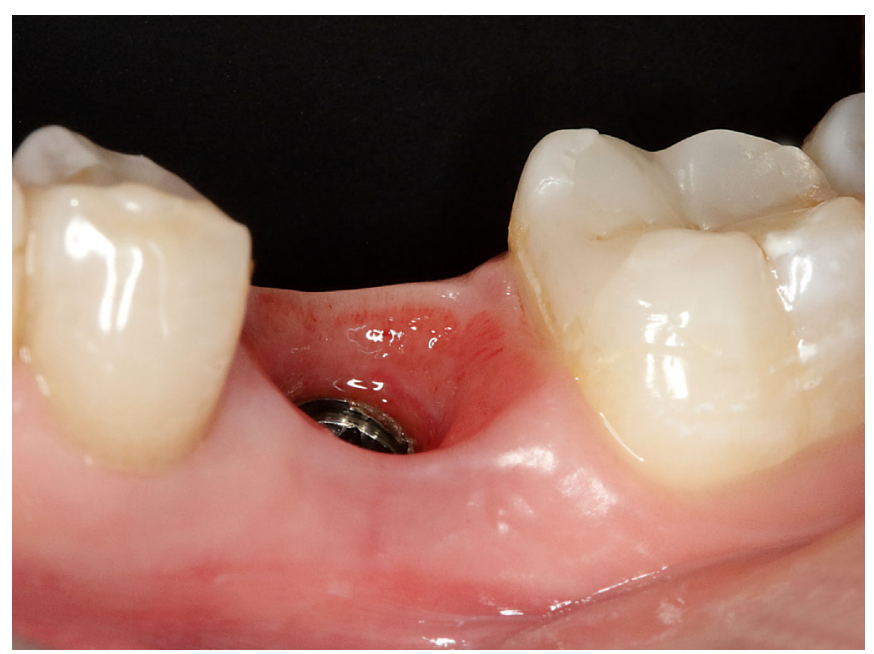

- Fixed with a measuring instrument-periodontal probe:

- The extent of keratinized mucosa was measured from the free gingival margin to the mucogingival junction using the roll technique [15]. Measurements were performed using a periodontal probe that provided values of a millimetre, after compressing the tissue from apical to cervical direction identifying the mucogingival junction more clearly; [fig. 5]

Fig. 5. Keratinized PIST buccally measured.

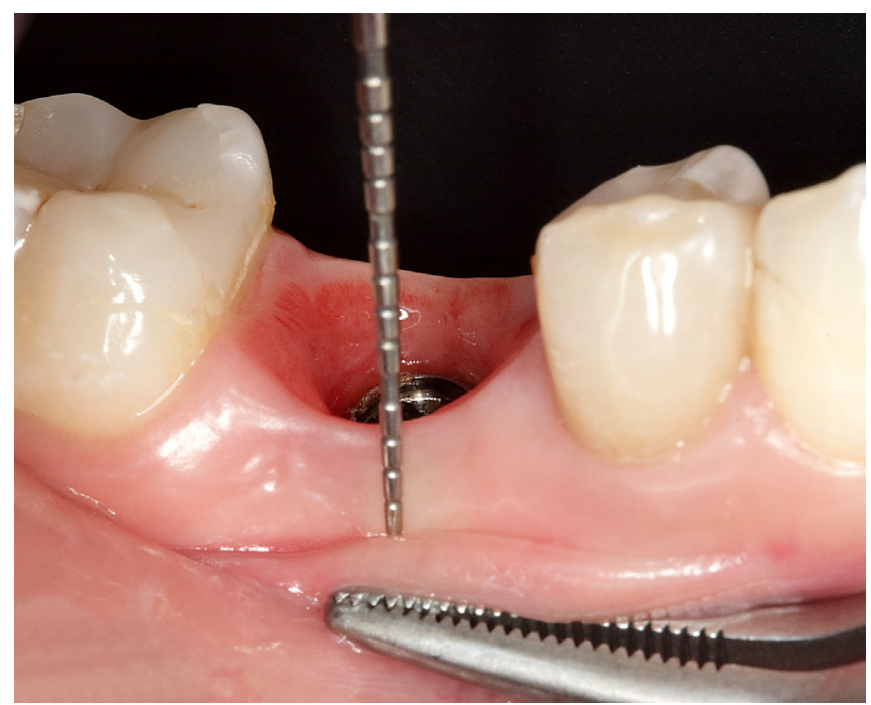

- The density of PIST was registered through an imprint of the periodontal probe, which appears on the dried soft tissue surface, and the time it regains its initial state.

- This technique allowed the marking of two types of mucosa - of high and low density. [fig. 6]

Fig. 6. Density PIST buccally measured.

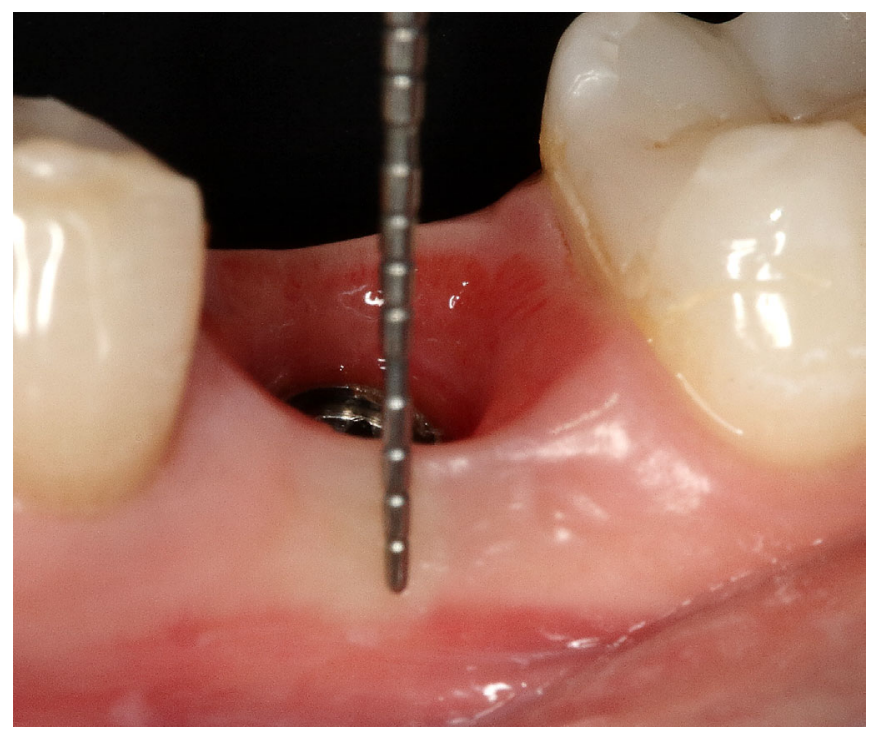

- The PIST height was measured in four projections mesially, buccally, distally and lingually using a periodontal probe, positioned in planes parallel to the implant lon- 
gitudinal axis and its tip in contact with the implant platform. The distances from the implant platform to the mu- cosal margin (B and $\mathrm{L}$ ) and to the level of inter-dental/implant or inter-implant/implant papilla were recorded. [fig. 7]

Fig. 7. Height of PIST- the measuring points were situated between the implant platform and the top of mucosa margin contour buccally, lingually, mesially and distally.
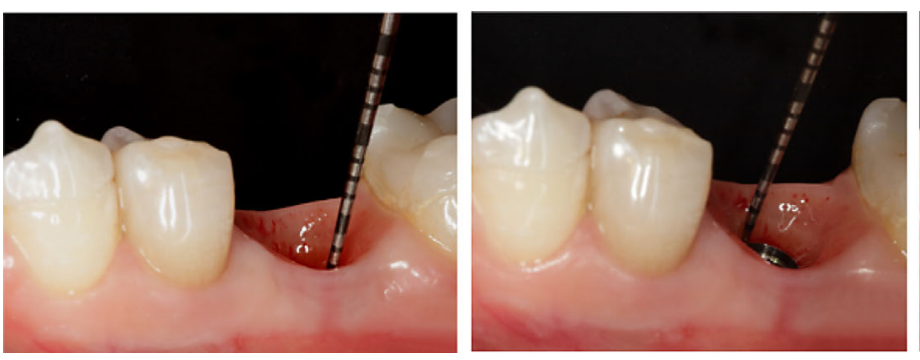

- The thickness PIST was measured in two projections - buccally and lingually using a periodontal probe, positioned parallelly to the implant platform. [fig. 8]

Fig. 8. In these measurements, the marking points were made on the contour of the free peri-implant mucosa in order to define its thickness at the level of implant platform.
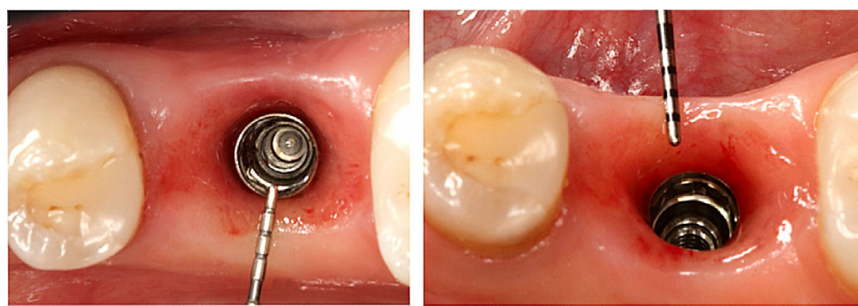

The calculated values were prepared in tabular form for statistical processing.

The aim of the method was to show the recognizability of indicators and the possibility of their being reported by dental practitioners with different experience in implant prosthetic treatment. This gives grounds to identify and incorporate in PIM those PIST characteristics which are directly relevant to the implementation of the prosthetic stages of implant treatment.

\section{RESULTS}

The survey results indicate which of the presented PIST characteristics were considered significant by the dentists. Their percentage distribution is presented in Figure 6. The highest percentage belongs to the Width of the keratinized PIST $-77,4 \%$, Height of PIST from the implant platform- 77,4\% and the thickness and height of PIST Mesially and Distally- 77,4\% , followed by the Thickness of PIST Buccally-54,8\%, the Thickness of PIST Buccally and Lingually-51,6\%, Colour of PIST-51,6\%, Density of PIST$41,9 \%$ and Texture of PIST-35,5\%. 22.6\% of the people surveyed indicated only three, while $19.4 \%$ noted all of the listed characteristics as significant [fig. 9] The differences between the assessments were evaluated with $\chi^{2}$ test.
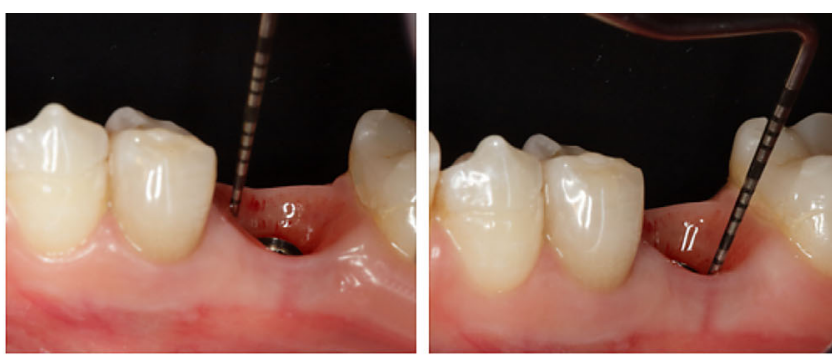

Fig. 9. The pie chart shows the rating of PIST characteristics in per cent.

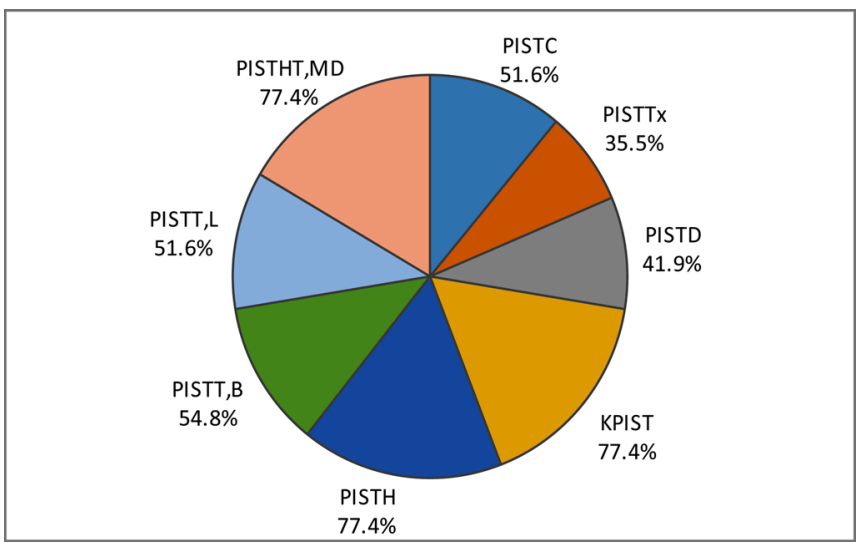

Analyzing the selected combinations of two indicators:

$64.5 \%$ of implantologists chose PIST height from the implant platform and PIST thickness and height Mesially and Distally;

$64.5 \%$ of implantologists chose PIST height from the implant platform and keratinized PIST width;

$61,3 \%$ selected keratinized PIST width and PIST thickness and height Mesially and Distally; [fig. 10]

Fig. 10. The bar chart shows different combinations of two parameters per cent.

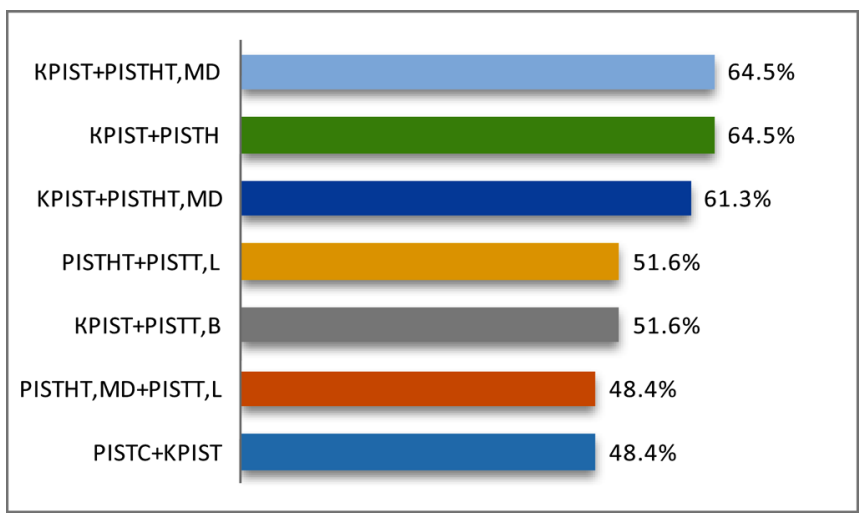


The statistical analysis of indicator recognizability shows the average matching percent for each parameter, recorded by four dentists for 10 implant sites. [Fig. 11] The average matching percent was as follows: PIST colour $82,5 \%$, PIST texture $-85,0 \%$, PIST density $-77,5 \%$, Kerati- nized PIST width-92,5\%. Figure 12 presents the average matching percent for PIST thickness-73,8\% (B-75,0\% and L-72,5\%) and PIST height $-75,6 \%$ (B-82,5\%, L- 72,5\%, M$70,0 \%, \mathrm{D}-77,5 \%)$

Fig. 11. The average matching per cent for PIST colour, PIST texture, PIST density and Keratinized PIST width.

\begin{tabular}{|c|c|c|c|c|}
\hline \multicolumn{5}{|l|}{ PIST colour } \\
\hline dentists matching & 4 dentists & 3 dentists & 2 dentists & \\
\hline implant site number & 5 & 3 & 2 & 10 \\
\hline implant site percent & 50,0 & 30,0 & 20,0 & 100,0 \\
\hline average matching percent & & 82,5 & & \\
\hline \multicolumn{5}{|l|}{ PIST texture } \\
\hline dentists matching & 4 dentists & 3 dentists & 2 dentists & \\
\hline implant site number & 6 & 2 & 2 & 10 \\
\hline implant site percent & 60,0 & 20,0 & 20,0 & 100,0 \\
\hline average matching percent & & 85,0 & & \\
\hline \multicolumn{5}{|l|}{ PIST density } \\
\hline dentists matching & 4 dentists & 3 dentists & 2 dentists & \\
\hline implant site number & 3 & 5 & 2 & 10 \\
\hline implant site percent & 30,0 & 50,0 & 20,0 & 100,0 \\
\hline average matching percent & & 77,5 & & \\
\hline \multicolumn{5}{|l|}{ Keratinized PIST width } \\
\hline dentists matching & 4 dentists & 3 dentists & 2 dentists & \\
\hline implant site number & 7 & 3 & & 10 \\
\hline implant site percent & 70,0 & 30,0 & & 100,0 \\
\hline average matching percent & & 92,5 & & \\
\hline
\end{tabular}

Fig. 12. The average matching per cent for PIST thickness and hight.

\begin{tabular}{|c|c|c|c|c|c|}
\hline \multicolumn{6}{|c|}{ PIST thickness Buccally and Lingually } \\
\hline dentists matching & 4 dentists & 3 dentists & \multicolumn{2}{|c|}{2 dentists } & \\
\hline implant site number & 4 & 11 & \multicolumn{2}{|l|}{5} & 20 \\
\hline implant site percent & 20,0 & 55,0 & \multicolumn{2}{|l|}{25,0} & 100,0 \\
\hline average matching percent & \multicolumn{4}{|c|}{73,8} & \\
\hline buccally/lingually & 75,0 & 7 & 72,5 & & \\
\hline \multicolumn{6}{|c|}{ PIST height in four projections $B, L, M, D$} \\
\hline dentists matching & 4 dentists & 3 dentists & 2 dentists & 0 dentists & \\
\hline implant site number & 13 & 17 & 9 & 1 & 40 \\
\hline implant site percent & 32,5 & 42,5 & 22,5 & 2,5 & 100,0 \\
\hline average matching percent & \multicolumn{4}{|c|}{75,6} & \\
\hline buccally/lingually/mesially/distally & $\mathrm{B} 82,5 \quad /$ & $\mathrm{L} 72,5$ & $\mathrm{M} 70,0 \quad /$ & D 77,5 & \\
\hline
\end{tabular}

The identification of parameters characterizing PIST from a prosthetic point of view and checking their recognisability enabled us to organize and arrange them in a Prosthetic implant map (PIM) [fig. 13] that contains all the information about the implant prosthetic conditions and the implant-supported prosthetic restoration. The sections of the map have been marked as: 1) Passport section containing brief information about the patient -patient's names, years and sex. It is assumed that the patient's main dental file is available and that the current prosthetic implant map is part of it. 2) A section containing information about the implant. It is intended to combine all data for a dental implant that are important in selecting the type and components of the implant suprà-structure. These include the implant position in dental arch, implant position buccolingually, implant angulation, implant system, implant type and model, implant and platform diameter, and its length. 3) A section containing information about the alveolar bone. The level of peri-implant alveolar crestal bone mesially and distally to the implant platform(IP)is presented 
in four groups: a)at IP level, b) above IP level, c) $1 \mathrm{~mm}$ below IP level; d) > 1,5 mm below IP level and reported by periapical X-ray. The bone registration is done at the implant recovery stage, implant provisional placement, final implant-supported restoration placement and regular checkups on fixed dates. 4) A section containing PIST information records its peculiarities in the particular implant area at a relevant stage of the implant treatment or its followup. Keratinized PIST width is presented in three variables - $0 \mathrm{~mm},<2 \mathrm{~mm}$ and $>2 \mathrm{~mm}$.; PIST density in two variableslow and high density; PIST height from implant platform

Fig. 13. Prosthetic implant map (PIM) sections.
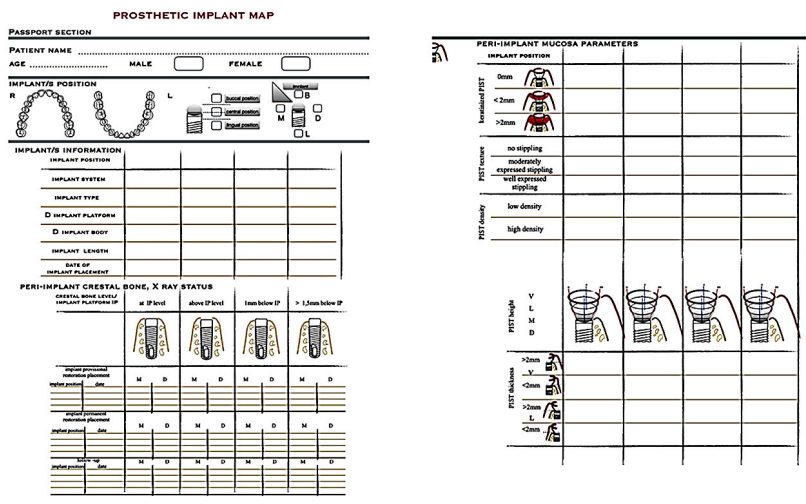

\section{DISCUSSION}

The planning of implant prosthetic restoration begins before placing the implant and is based on a precise analysis of the patient's general medical status, extraoral, intraoral status, occlusal relationship between the upper and lower jaw, available alveolar bone, quantity and quality of the soft tissues in the implantation area. Proceeding to prosthetics of the already placed implant requires reassessment of the prosthetic field, which consists of the dental implant and the surrounding hard and soft tissues. The prosthetic implant map records in a certain order the characteristics of these two main components and makes it easier to decide on the type of temporary and permanent implant restoration. PIM is fully practical, and its structurå leads to convenience for the clinician to complete it. For each parameter, there are variables/ranges, graphs, or possible configurations that only require pick-and-tick. As such, it resembles the rating indices.

The implant type and its 3D location are related to the choice of implant supra-structure - standard / individualized, the fixation of the implant crown - screw-retained or cement-retained, and the design of the emergence profile of the implant supra-structure. $[16,17,18,19]$ It is advisable to have a slightly concave contour under conditions of the correct prosthetic position of the implant and the presence of sufficient quantity and quality of the periplanar soft tissues. The disposition of the implant and its angulation are a prerequisite for changing the germination profile, which should optimally maintain and shape the soft tissues. [20] Thus, it can have a different degree of concavity and convexity in vertical and horizontal projection defined as contour and subcontours. [21] In addition in four projections, scaled in 0,1,2,3,4 mm; PIST thickness buccally and lingually separated in two ranges - $>2 \mathrm{~mm}$ or $<2$ mm. 5) The implant-supported restoration section makes it possible to note in detail the used prosthetic components of the respective implant system, the selected materials for implant-supported prosthetic restoration (provisional or permanent). 6) The last follow-upsection controls the result of implant treatment over time. It includes the status of implant-supported restoration, occlusal relations, the position of the mucosal margin under gentle air-flow, plaque index, papilla index.
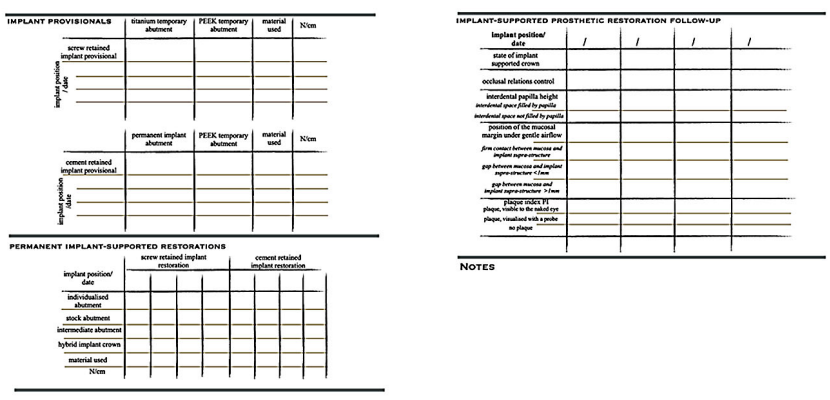

to the parameters of the implant used, PIM has a sector indicating its deviation in the respective direction. Moreover, materials and surface topography of implant abutment materials may also influence the biological seal formed at the implant-soft tissue interface as Lambert mentions.

The condition of the peri-implant alveolar bone found radiographically is an indication of implant osteointegration and a feature that can be monitored over time. The crestal alveolar bone level assessment versus the implant platform, an approach used in many studies, has been applied in PIM. PIM distinguishes four possibilities that can be easily identified by the clinician and the stages in which X-ray control is recommended. [22, 23]

The importance and role of peri-implant soft tissues are firmly established in the professional literature. This is proved by the poll results, which allowed the development of a list of PIMT parameters that are directly related to the prosthetic stages of the implant treatment. Combinations PIST height/ MDheight, thickness, and keratinized PIST buccally / PIST height were chosen by $64,5 \%$ of the people surveyed.

\section{PIST colour and texture}

The colour and texture of the peri-implant soft tissue are used to evaluate the result of implant-supported prosthetic treatment. Fürhauser, Rudolf et al. [24] matched PIST colour and texture to that of the reference tooth. They concluded that the matching is in no more than just over one-third of cases, and it shows major discrepancies in $20 \%$. Park S. et al. observed that the colour of soft tissue around the titanium implant is significantly different compared to the gingiva of natural teeth. [25] Another study 
conducted by Edward J et al. [22] showed an assessment of peri-implant soft tissue based on implant aesthetic score. The scoring was done according to the criteria proposed by Testori. [26] Texture of the peri-implant soft tissue: - 0 = complete loss of texture, $1=$ does not look healthy, but some texture still preserved. 2 = looks like healthy gingival tissue around the natural teeth. Color of the peri-implant soft tissue: $0=$ completely different colour from healthy tissue, $1=$ does not look healthy but still aesthetically acceptable, 2 = looks like healthy gingival tissue around the natural teeth. The map (PIM) we have designed uses the three-degree scale to record the two parameters. The scale is based on the characteristics of the gingiva around teeth, for colour - 1) pale pink, 2) pink, 3) dark, coral pink and for texture-1) smooth surface of the mucosa, 2) moderatelyexpressed stippling, 3) well-expressed stippling. With all the above parameters being available before implant placement or at the stage of the second surgery, PIM follows their condition throughout the treatment and after fixing the final implant-supported restoration over time.

\section{PIST density}

The connective tissue is the main component of periimplant mucosa. It consists of dense type I collagen fibres that are less vascular and parallel to the long axis of the implant. [27] Its quantity and volume are a prerequisite for forming and maintaining contour and shape of the peri-implant mucosa. Optimal pressure from the abutment is required for that. The abutment supports the peri-implant mucosa through tight contact with it.

Keratinized PIST width. The presence of keratinized mucosa surrounding an implant is thought to be one of the important factors in maintaining peri-implant soft tissue health. Chiu et al. [28] surveyed the clinical findings and assessed the current evidence regarding the role of keratinized mucosa in the maintenance of dental implants. They concluded that there were conflicting results in the literature available. Several other studies defined the band of keratinized mucosa as narrow keratinized mucosa $(<2 \mathrm{~mm})$ and wide keratinized mucosa (>2 mm). [23, 29, 30, 31,]

( PIM also separated keratinized PIST width into two main groups: absence $(0 \mathrm{~mm})$ and presence of keratinized PIST with two subgroups of the latter: $<2 \mathrm{~mm}$ and $>2 \mathrm{~mm}$ bandwidth. The correlations between keratinized PIST with on the one hand and plaque control and peri-implant inflammation on the other showed that the access to oral hygiene at implant sites is more important than the width of keratinized mucosa. PIM used the air-flow test to assess the interface peri-implant mucosa margin/implant supra-structure surface. The contact between them is normally tight in cases of keratinized and dense peri-implant mucosa, and loose in cases of non-keratinized, movable peri-implant mucosa. This fact, in itself, suggests a different approach to plaque control and also re-evaluation of the existing emergence profile of implant-supported restoration. All the clinical and radiographic parameters of peri-implant disease significantly increased when the KM band was $<2 \mathrm{~mm}$, and the presence of $<2 \mathrm{~mm}$ of $\mathrm{KM}$ around dental implants in erratic maintenance compliers seems to be associated with peri implant diseases, concluded Monje et Blasi [23] Current treatment concepts predominantly focus on providing optimized peri-implant soft-tissue volume and keratinized tissue before the start of the prosthetic phase and insertion of the final reconstruction through surgical and prosthetic techniques. [32]

\section{PIST height and thickness}

The data available in the literature confirm the relationship between the PIST thickness and marginal bone stability around implants. The PIST thickness and height are also important for creating the optimal emergence profile of the implant supra-structure.

The vertical dimension of the PIST is related to differences in the cervical contour position in B, L, M, D projections. For each of them, there are marked divisions of 0-5 $\mathrm{mm}$. The map is highlighted by a topographic diagram that requires the corresponding height mark.

PIM defines the thickness of PIST buccally and lingually, dividing it into two subgroups: $>2 \mathrm{~mm}$ and $<2 \mathrm{~mm}$. Investigating crestal bone changes in bone level and tissue level, implants Van Eekeren also distinguished two thicknesses $>2 \mathrm{~mm}$ and $<2 \mathrm{~mm}$. [33] The PIST thickness was measured with a periodontal probe before implant placement by Linkevicius T. The test implants were divided into two groups - with thin and thick PIST. He concluded that if the tissue thickness is $2.0 \mathrm{~mm}$ or less, crestal bone loss up to $1.45 \mathrm{~mm}$ may occur, despite a supra-crestal position of the implant-abutment interface. [34]

Four dentists confirmed the recognizability of the above-mentioned characteristics, which were arranged in the form of a legend with a detailed description of the way they were registered. Their professional experience - both general and specialized - was used as a basis for choosing and justifying the possibility for the map to be used by a wide range of dental practitioners.

Accurate interpretation of assessment parameters is vital for determining implant success and/or complications. Parameters that need continual monitoring are: soft tissue architecture, bleeding, probing depth, radiographic images, occlusion, mobility, bone loss, peri-implant status, restoration adequacy, patient health status and satisfactory oral hygiene. [35]

The main requirement for long-lasting aesthetic and functional results has inspired many authors to use different indicators from those in PIM to record the stability of peri-implant tissues and components of implant-supported restoration. Some of them emphasize aesthetic (PES, PFI, WES), other functional aspects of the implant-supported restorations. [24, 36, 37, 38, 39] Mazur Z. et al. created an index for evaluation and monitoring the success of implant treatment by means of the condition of peri-implant tissues, based on the scientific knowledge

accumulated to date and the study of a representative group of patients with implant prosthetic treatment .

The indicators used for evaluation are as follows: 1) condition of the peri-implant alveolar bone; 2) the presence of an inflammatory process; 3) pre-implant mucosa 
status, represented by attached mucosa width; 4) presence of PIM recessions buccally; 5) profile of the alveolar ridge at the implant area. [40]

PIM uses diagrams and ranges that outline the following boundary/marginal configurations:

Unfavourable conditions for prosthesis:

- Implant disposition

- Crestal bone level > 1,5mm under implant platform level

\section{- No keratinized PIST \\ - No PIST texture \\ - Low density \\ - PIST height $<1 \mathrm{~mm}$ \\ - PIST thickness $<2 \mathrm{~mm}$}

Favourable conditions for prosthesis:

- Prosthetic implant position

- Crestal bone level $>$ /= at implant platform level

- Keratinized PIST>2mm

- PIST texture well expressed

- High density

- PIST height $>3 \mathrm{~mm}$

- PIST thickness $>2 \mathrm{~mm}$

There are many possible combinations between the above-mentioned implant prosthetic field parameters, which result in the corresponding prosthetic protocols. Based on facts such as: "Only thick gingival biotype can be manipulated", postulated by Berglundh et al. and Simeone et al. or "In fact, thin gingival biotype is not suitable for sculpting because its compression does not lead to a controlled scalloping but to a high risk of soft tissue collapse and gingival recession", it can be summarized that the range: intermediate-favourable prosthetic condition offers ultimate conditions for integrating the implant suprastructure not only to the implant but also to the adjacent PIST. Creating an emergence profile that shapes and main- tains tight contact with soft tissues is a guarantee for the stability of the PIST barrier. [41, 42]

\section{CONCLUSION:}

The organization and formatting of the map allow highly accurate marking of all data significant for the implant prosthetic treatment and their follow-up over time. The Prosthetic implant map can be used: 1) by every dentist practising implant treatment; 2) as a template for consistent registering of all parameters of implant prosthetic area; 3) as a successful guideline for implant supra-structure planning; 4) for topographic registration of PIST which is essential for emergence profile creation; 5) for comparative analysis and follow-up of implant-supported restoration and peri-implant tissue (hard and soft). From a practical point of view, it is a very convenient way of storing all the necessary information and its subsequent analysis for both clinician and patient.
Abbreviations:
PIST - peri-implant soft tissue
PIM - prosthetic implant map
IP - implant platform
B - buccal
L - lingual
M - mesial
D - distal

\section{Conflict of interest statement}

The authors have declared that no competing interests exist.

\section{Acknowledgments}

This work was supported by Grant-2018 Scientific Research No. D-86 from the Medical University-Sofia, Bulgaria.

\section{REFERENCES:}

1. Bishti S, Strub JR, Att W. Effect of the implant-abutment interface on peri-implant tissues: a systematic review. Acta Odontol Scand. 2014 Jan; 72(1):13-25. [PubMed] [Crossref]

2. Morton D, Chen ST, Martin WC, Levine RA, Buser D. Consensus statements and recommended clinical procedures re- garding optimizing esthetic outcomes in implant dentistry. Int $\mathbf{J}$ Oral Maxillofac Implants. 2014; 29: 216-220. [PubMed] [Crossref]

3. Covani U. Barone A. Cornelini R. Crespi R. Soft Tissue Healing Around Implants Placed Immediately After Tooth Extraction Without Incision: A Clinical Report. Int J Oral Maxillofac Implants. 2004Jul-Aug; 19(4):549-53 [PubMed]
4. Priest, G. Predictability of soft tissue form around single tooth implant restorations. International Journal of Periodontics and Restorative Dentistry. 2003; 23: 19-27.

5. Kan JY, Rungcharassaeng K, Lozada JL, Zimmerman G. Facial gingival tissue stability following immediate placement and provisionalization of maxillary anterior single implants: a 2- to 8-year follow-up. Int J Oral Maxillofac Implants. 2011 JanFeb;26(1):179-87. [PubMed]

6. Adell R, Lekholm U, Rockler B, Branemark PI, Lindhe J, Eriksson B, et al. Marginal tissue reactions at osseointegrated titanium fixtures (I). A 3year longitudinal prospective study. Int J Oral Maxillofac Surg. 1986 Feb;

\section{5(1): 39-52. [PubMed] [Crossref]}

7. Bengazi F, Wennstrom JL, Lekholm U. Recession of the soft tissue margin at oral implants. A 2-year longitudinal prospective study. Clin Oral Implants Res. 1996 Dec;7(4):30310. [PubMed] [Crossref]

8. Cardaropoli G, Lekholm U, Wennstrom JL. Tissue alterations at implant-supported single-tooth replacements: a 1-year prospective clinical study. Clin Oral Implants Res. 2006 Apr;17(2):165-71. [PubMed] [Crossref]

9. Cooper L, Felton DA, Kugelberg CF, Ellner S, Chaffee N, Molina AL, et al. A multicenter 12-month evaluation of single-tooth implants restored 3 weeks after 1-stage surgery. Int J Oral 
Maxillofac Implants 2001 Mar-Apr; 16(2):182-92. [PubMed]

10. Ekfeldt A, Eriksson A, Johansson LA. Periimplant mucosal level in patients treated with implantsupported fixed prostheses: a 1-year follow-up study. Int J Prosthodont 2003 Sep-Oct;16(5):529-32. [PubMed]

11. Grunder U. Stability of the mucosal topography around single-tooth implants and adjacent teeth: 1-year results. Int J Periodontics Restorative Dent 2000 Feb; 20(1): 11-17. [PubMed]

12. Oates TW, West J, Jones J, Kaiser D, Cochran DL. Long-term changes in soft tissue height on the facial surface of dental implants. Implant Dent 2002; 11(3): 272-9. [PubMed] [Crossref]

13. Small PN, Tarnow DP. Gingival recession around implants: A 1-year longitudinal prospective study. Int J Oral Maxillofac Implants $2000 \mathrm{Jul}-$ Aug; 15(4):527-532. [PubMed]

14. Lambert J,Stumpel, Wadhwani, Chandur. Development and capture of soft tissue contours at time of implant placement. J of Prost Dent. 2017; 117(6):709-713.

15. Brescovitt R, Thome G, Melo A, Silva R. Soft tissue behaviour around dental implants placed in fresh extraction sockets and immediately restored in aesthetic area: a preliminary short-term evaluation. Rev Odontol UNESP. 2017; 46(4):196-202.

16. Tarnow D, Elian N, Fletcher P, Froum S, Magner A, Cho SC, et al. Vertical distance from the crest of bone to the height of the interproximal papilla between adjacent implants. J Periodontol. 2003 Dec;74(12):1785-8. [PubMed] [Crossref]

17. Tarnow DP, Eskow RN, Zamzok J. Aesthetics and implant dentistry. Periodontol 2000. 1996 Jun; 11:85-94. [PubMed] [Crossref]

18. Tarnow DP, Magner AW, Fletcher P. The effect of the distance from the contact point to the crest of bone on the presence or absence of the interproximal dental papilla. J Periodontol. 1992 Dec; 63(12):995- 996. [PubMed] [Crossref]

19. Azer S. S. A Simplified Technique for Creating a Customized Gingival Emergence Profile for Implant-Supported Crowns. J Prostho- dont. 2010 Aug;19(6):497-501. [PubMed] [Crossref]

20. Steigmann M, Monje A, Chan $\mathrm{H}$, Wang H. Emergence Profile Design Based on Implant Position in the Esthetic Zone. Int J Periodontics Restorative Dent. 2014 Jul-Aug;34(4): 559-563. [PubMed] [Crossref]

21. Huan S. Oscar G. Arnold W. Ernesto L. Considerations of Implant Abutment and Crown Contour: Critical Contour and Subcritical Contour. Int J Periodontics Restorative Dent. 2010 Aug;30(4):335-43. [PubMed]

22. Edward J, George JM, Prakash DG. Evaluation of peri-implant soft tissues and hard tissues in titanium implants in immediate and delayed cases: A comparative study. J Dent Implant. 2017; 7:3-10.

23. Monje A, Blasi G. Significance of keratinized mucosa/gingiva on periimplant and adjacent periodontal conditions in erratic maintenance compliers. J Periodontol. 2019 May;90(5): 445-453. [PubMed] [Crossref]

24. Furhauser R, Florescu D, Benesch T, Haas R, Mailath G, Watzek G. Evaluation of soft tissue around single-tooth implant crowns: the pink esthetic score. Clin Oral Implants Res. 2005 Dec;16(6):639-44. [PubMed] [Crossref]

25. Park S, Da Silva JD, Weber HP, Ishikawa-Nagai S. Optical phenomenon of peri-implant soft tissue. Part I. Spectrophotometric assessment of natural tooth gingiva and peri-implant mucosa. Clin Oral Implants Res. 2007 Oct;18(5):569-74. [PubMed] [Crossref]

26. Testori T, Bianchi F, Del Fabbro M, Capelli M, Zuffetti F, Berlucchi I, et al. Implant aesthetic score for evaluating the outcome: Immediate loading in the aesthetic zone. Pract Proced Aesthet Dent. 2005 Mar;17(2):123-30. [PubMed]

27. Berglundh T, Abrahamsson I, Welander M, Lang NP, Lindhe J. Morphogenesis of the peri-implant mucosa: An experimental study in dogs. Clin Oral Implants Res. 2007 Feb; 18(1):18. [PubMed] [Crossref]

28. Chiu Y, Lee S, Lin Y, Lai Y. Significance of the width of keratinized mucosa on peri-implant health. $J$ Chin Med Assoc. 2015 Jul; 78(7):389394. [PubMed] [Crossref]

29. Schrott AR, Jimenez M, Hwang
JW, Fiorellini J, Weber HP. Five-year evaluation of the influence of keratinized mucosa on peri-implant soft-tissue health and stability around implants supporting full-arch mandibular fixed prostheses. Clin Oral Implants Res. 2009 Oct;20(10):1170-7. [PubMed] [Crossref]

30. Buyukozdemir Askin S, Berker E, Akincibay H, Uysal S, Erman B, Tezcan I, et al. Necessity of keratinized tissues for dental implants: a clinical, immunological, and radiographic study. Clin Implant Dent Relat Res. 2015 Feb; 17(1):1-12. [PubMed] [Crossref]

31. Mericske-Stern R, Steinlin Schaffner T, Marti P, Geering AH. Periimplant mucosal aspects of ITI implants supporting overdentures. A fiveyear longitudinal study. Clin Oral Implants Res. 1994 Mar; 5(1):9-18. ( [PubMed] [Crossref]

32. Thoma DS, Muhlemann S, Jung RE. Critical soft-tissue dimensions with dental implants and treatment concepts. Periodontol 2000. 2014 Oct; 66(1):106-18. [PubMed] [Crossref]

33. van Eekeren $P$, van Elsas $P$, Tahmaseb A, Wismeijer D.The influence of initial mucosal thickness on crestal bone change in similar macrogeometrical implants: a prospective randomized clinical trial. Clin Oral Implants Res. 2017 Feb; 28(2): 214-218. [PubMed] [Crossref]

34. Linkevicius $\mathrm{T}$, Apse $\mathrm{P}$, Grybauskas S, Puisys A. The influence of soft tissue thickness on crestal bone changes around implants: a 1-year prospective controlled clinical trial. Int $J$ Oral Maxillofac Implants. 2009 JulAug;24(4):712-9. [PubMed]

35. The evaluation, assessment, and care of dental implants google on: all June 14, 2012By Lynn Mortilla, RDH, Advanced Concepts in the Evaluation, Assessment \& Care of Dental Implants at the ADHA meeting in Phoenix on June 14, 2012.

36. Albrektsson T. Zarb G. Worthington P. Eriksson AR. The Long-Term Efficacy of Currently Used Dental Implants: A Review and Proposed Criteria of Success. Int J Oral Maxillofac Implants. 1986 Summer; 1(1):11-25. [PubMed]

37. Belser U, Buser D, 
Higginbottom F. Consensus statements and recommended clinical procedures regarding esthetics in implant dentistry. Int J Oral Maxillofac Implants. 2004; 19:73-74. [PubMed]

38. Belser U, Schmid B, Higginbottom F, Buser D. Outcome analysis of implant restorations located in the anterior maxilla: a review of the recent literature. Int J Oral Maxillofac Implants. 2004; 19:30-42. [PubMed]
39. Jemt T. Regeneration of gingival papillae after single-implant treatment. Int J Periodont and Rest Dentistry. 1997 Aug;17(4):326-33. [PubMed]

40. Mazur Z, Korabek L, Mazur D. Peri-implant tissue score (PITS) as a measure of success, applied to 869 dental implants from a retrospective clinical study. Quintessence Int. 2018; 49(7):567-579. [PubMed] [Crossref]

41. Parpaiola A, Sbricoli L, Guazzo
R, Bressan E, Lops D. Managing the Peri-implant Mucosa: A Clinically Reliable Method for Optimizing Soft Tissue Contours and Emergence Profile. $J$ Esthet and Restor Dent. 2013 Oct; 25(5):317-323. [PubMed] [Crossref]

42. Stumpel LJ, Wadhwani C. A Customized Healing Abutment for Immediate and Delayed Implant Cases. Compend Contin Educ Dent. 2017 Nov/Dec;38(10):672-678. [PubMed]

Please cite this article as: Nikolova N, Filchev D. Prosthetic Implant Map (PIM) - Accurate and Convenient Assistant in Successful Implant Treatment. J of IMAB. 2020 Jan-Mar;26(1):2946-2955

DOI: https://doi.org/10.5272/jimab.2020261.2946

Received: 24/04/2019; Published online: 25/02/2020

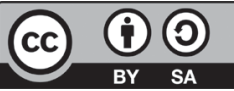

Adress for correspondence:

Dr Neli Nikolova

Department of Prosthetic Dentistry, Faculty of Dentistry, Medical University-Sofia 1, G. Sofiiski Blvd., 1431 Sofia, Bulgaria e-mail: nenik@abv.bg 